\title{
Stimulus control along a drug-dose dimension
}

\author{
FAREN R. AKINS \\ National Aeronautics and Space Administration, Ames Research Center, Moffett Field, California 94035
}

WILLIAM DREW GOUVIER

Memphis State University, Memphis, Tennessee 38152

and

\author{
JOSEPH E. LYONS \\ College of Petroleum and Minerals, Dhahran, Saudi Arabia
}

\begin{abstract}
Pigeons were trained to discriminate between two dosage levels of phenobarbital, each associated with a different density of reinforcement. Postdiscrimination generalization testing revealed stimulus control exerted along the drug-dosage dimension. Two of four subjects produced gradients showing a peak shift.
\end{abstract}

Considerable research has studied the acquisiton of discriminative responding using exteroceptive stimuli, yet only recently has interest turned to the analysis of stimulus control by interoceptive stimuli. Comparisons between the stimulus control properties of interoceptive and exteroceptive stimuli have often been thwarted by the lack of comparable training and testing procedures, as well as by dissimilarity among the dependent variables typically employed.

Trost and Ferraro (1974) demonstrated stimulus control exerted by dosage level of pentobarbital following discrimination training between two doses of the drug. Similar results have been reported using dosage levels of d-1-amphetamine as discriminative stimuli in the rat (Waters, Richards, \& Harris, 1972). The use of leverchoice responses in these two studies dichotomized the distribution of possible responses, rendering impossible the demonstration of graded response tendencies indicative of stimulus control along the dosage dimension. It is difficult to compare these data with generalization gradients typically found with tests for stimulus control along most exteroceptive stimulus dimensions. Such comparisons are facilitated when a continuous dependent variable (e.g., response rate) is used in conjunction with examination of the control exerted by novel points along the dimension. Comparison between generalization gradients so obtained might then be conducted with greater confidence.

The purpose of the present work was to demonstrate a response rate measure of stimulus control that avoids the interpersonal limitations inherent in the choice procedures cited above. Pigeons were trained to discriminate between two dosage levels of phenobarbital by cor-

Requests for reprints should be sent to William Drew Gouvier, Department of Psychology, Memphis State University, Memphis, Tennessee 38152. relating each dosage with a different reinforcement density. The use of low-density reinforcement associated with the $\mathrm{S}$ - training dosage insured that responding would continue in its presence. It was hypothesized that the $\mathrm{S}+$ and $\mathrm{S}-$ dosage levels would display stimulus control properties appropriate to the reinforcement schedule correlated with each. Postdiscrimination generalization testing was conducted to assess the stimulus control exerted by various doses along the dosage dimension, providing a basis for inference about the excitatory and inhibitory properties associated with the S+ and Sdoses, respectively.

\section{METHOD}

Subjects

Four experimentally naive White King pigeons, maintained at $70 \%$ to $75 \%$ of their free-feeding weights, served as the experimental subjects.

\section{Apparatus}

All training and testing was conducted in two single-key operant pigeon chambers (Grason Stadler Model PB1100) with associated automatic programming and recording equipment. A green light of $555 \mathrm{~nm}$ transilluminated the pecking key throughout the experiment. Sound-attenuating insulation and masking noise were provided for each chamber. Mixed grain, presented for 3-sec intervals, served as reinforcement.

Phenobarbital sodium was prepared for injection using an isotonic $(.9 \%)$ saline vehicle. Serial dilutions were performed to allow injection volume to be held to a constant $1 \mathrm{cc} / \mathrm{kg}$ body weight. Solutions containing $5,10,20,25$, and $30 \mathrm{mg} / \mathrm{cc}$ phenobarbital were prepared not more than 1 week before use.

\section{Procedure}

Following preliminary magazine and keypeck training, the average reinforcement density was decreased from continuous reinforcement (CRF) to variable-interval (VI) $60 \mathrm{sec}$ as follows: Days 1, 2, 3-50 CRF; Day 4- (VI $15 \mathrm{sec}$ ) for $15 \mathrm{~min}$; Day 5(VI $30 \mathrm{sec)}$ for $30 \mathrm{~min}$; Day 6- (VI $15 \mathrm{sec}$ ) for $60 \mathrm{~min}$. On day 6,15 days of nondiscrimination baseline training began. During this baseline phase, each subject was given an intramus- 




Figure 1; Response rates under each drug-dose level during generalization testing.

cular injection of phenobarbital in the breast region $30 \mathrm{~min}$ prior to training. Birds B-5 and G-22 received a dosage of $20 \mathrm{mg} / \mathrm{kg}$ body weight; Birds G-23 and G-24 were given $10 \mathrm{mg} / \mathrm{kg}$.

The following phase involved 30 days of drug-dose discrimination training. For B-5 and G-22, the $20-\mathrm{mg} / \mathrm{kg}$ dosage remained correlated with the VI 60-sec reinforcement schedule (S+ condition), while on randomly alternating days a $10-\mathrm{mg} / \mathrm{kg}$ dosage was administered. This dosage was correlated with a VI 300-sec schedule ( $\mathrm{S}-$ condition). These conditions were reversed for Birds G-23 and G-24, producing a balanced design.

Generalizaton testing along the drug-dose dimension followed the discrimination training phase. Seven dosage levels of phenobarbital were used: 0 (saline vehicle alone), 5, 10, 15, 20, 25 , and $30 \mathrm{mg} / \mathrm{kg}$. Testing was conducted over the next 21 days, in seven blocks of 3 days each. Within each block, an S+ and an $\mathrm{S}$ - training day were presented along with one of the seven test dosages. The specific sequence of test-dose treatment was randomly determined both within and across subjects.

The VI 60-sec schedule was always in effect on test days in order to preclude the development of differential responding in testing based on schedule-produced cues, as well as to insure that responding occurred throughout the seven test sessions. Orderly generalization gradients along the dosage dimension would not be produced if the subjects were using the reinforcement schedule, rather than drug dose, as the major discriminative cue. Response rates for each test session were recorded and plotted to produce the generalization gradients.

\section{Results}

There were no consistent differences noted during either training or testing as a function of drug-dose sequence. Figure 1 presents the generalization test results. These data show that the subjects' response rates were under the stimulus control of the drug doses. Generalization testing produced orderly gradients for all subjects, with substantially higher responding evidenced under the S+ dosage than under the $\mathrm{S}$ - dosage level. Note also that Birds G-22 and G-23 showed a displacement of the modal response category away from the S+ dosage, so as to be further removed from the $\mathrm{S}-$ dosage.

\section{DISCUSSION}

The results of the present work support the notion that drug-produced interoceptive stimuli can acquire discriminative properties analogous to those observed using similar training with exteroceptive stimulus dimensions. The acquisition of discriminative stimulus properties is particularly striking, because the discrimination was acquired across days, rather than within days, as is typical of exteroceptive discriminations.

Postdiscrimination generalization testing revealed that the $\mathrm{S}$ - dosage acquired response-suppressive properties during training. The $\mathrm{S}-$ dosage produced the lowest response rates in testing for Birds G-22 and G-24. The presence of a peak shift in Subjects G-22 and G-23 provides further evidence that inhibitory properties accrue to the $\mathrm{S}-$ dosage (Bloomfield, 1969; Hearst, 1969; Terrace, 1972a, 1972b). These two effects were independent of whether the S- was a high or low dosage level.

These results are entirely consistent with previous work on drug-state stimulus control (Trost \& Ferraro, 1974; Waters et al., 1974; see also Winter, 1974). By avoiding methodological and interpretational limitations inherent in the studies cited above, the present work provides strong evidence that interoceptive stimuli associated with drug ingestion can control behavior in a manner analogous to the control exerted by exteroceptive stimuli. The use of response rates in postdiscrimination generalization testing facilitates such comparisons, for these are the measures most typically used in demonstrating stimulus control by exteroceptive stimuli as well.

\section{REFERENCES}

Bloomfield, T. M. Behavioral contrast and the peak shift. In R. Gilbert \& N. Sutherland (Eds.), Animal discrimination learning. New York: Academic Press, 1969.

Hearst, E. Excitation, inhibition and discrimination learning. In N. Mackintosh \& W. Honig (Eds.), Fundamental issues in associative learning. Halifax: University Press, 1969.

Terrace, H. S. By-products of discrimination learning. In G. Bower (Eds.), The psychology of learning and motivation (Vol. 5). New York: Academic Press, 1972. (a)

Terrace, H. S. Conditioned inhibition in successive discrimination learning. In R. Boakes \& M. Halliday (Eds.), Inhibition and learning. New York: Academic Press, 1972. (b)

Trost, J. G., \& Ferraro, D. P. Discrimination and generalization of drug stimuli in monkeys. In J. Singe, L. Miller, \& H. Lal (Eds.), Drug addiction (Vol. 3). New York: Futura, 1974.

Waters, W. H., Richards, D. W., \& Harris, H. T. Discriminative control and generalization of the stimulus properties of D-1-amphetamine. In J. Singe, L. Miller, \& H. Lal (Eds.), Drug addiction (Vol. 1). New York: Futura, 1972.

Winte R, J. C. Hallucinogens as discriminative stimuli. Federation Proceedings, 1974, 33, 1825-1832.

(Received for publication October 22, 1979.) 